\title{
Между гиперглобализацией
}

и национальной политикой: как снизить
популистские риски для глобального
экономического управления после COVID-19?'1

\section{М. Ревизорский}

Ревизорский Марек - доктор, доцент Института политологии факультета социологии Гданьского университета; Poland, 78-100 Kolobrzeg, ul. Wielkopolska, 2C/15; E-mail: marcuser@o2.pl

Исследователи глобального управления порой выступают за изменение баланса с глобального на национальный уровень. Они подчеркивают несовместимость глобального экономического управления с демократиями, которые имеют право защищать свое социальное устройство и суверенитет. Кроме того, они осознают, что глобальное (экономическое) управление находится под шквальным огнем нового vох рориіi, подчеркивая социально-экономические и культурные источники их противодействия либеральному международному порядку. Осознавая своевременность такой аргументации, мы исследуем фундаментальную проблему растущего популизма с его опорой на суверенитет. Смещение акцента на внутренние проблемы произошло во время пандемии COVID-19. Это во многом свело на нет преимущества международного сотрудничества.

Понимая роль фрагментированной системы экономического управления в разжигании популизма, мы ставим перед собой задачу поразмышлять не только над решением проблемы глобального экономического управления, но и над (1) обоснованием решительных сдвигов в сторону национального управления, (2) скрытыми рисками экономической глобализации и (3) выработкой альтернативного решения, а именно выбора среднего пути между гиперглобализацией и национальной политикой.

Ключевые слова: глобальное экономическое управление; интегрированное управление; фрагментация; цифровизация; суверенитет; популизм; ВТО; «Группа двадцати»

Для цитирования: Ревизорский М. (2021). Между гиперглобализацией и национальной политикой: как снизить популистские риски для глобального экономического управления после COVID-19? // Вестник международных организаций. Т. 16. № 2. С. 132-156 (на русском и английском языках). DOI: 10.17323/1996-7845-2021-02-07

\section{Введение}

Концепция глобального управления проделала долгий путь от первоначального всеобъемлющего понятия [Finkelstein, 1995] до вполне структурированного взгляда на мировую политику [Dingwerth, Pattberg, 2006]. Постепенно отступая от традиционных принципов и представлений о властных отношениях, она отражает различные формы

${ }^{1}$ Rewizorski M. Between Hyperglobalization and National Policy. Is There a Way to Mitigate Populist Risks for Global Economic Governance in the Post-COVID-19 World?

Статья поступила в редакцию в феврале 2021 г. Перевод статьи выполнен с согласия автора С.А. Васильковским, н.с. Центра исследований международных институтов Российской академии народного хозяйства и государственной службы при Президенте Российской Федерации (РАНХиГС). 
управления вне границ государств, такие как нормы, режимы, организации, транснациональные сети и сети защиты интересов, а также сообщества практиков, которые, учитывая отсутствие единого организационного принципа глобального управления, опираются на многочисленные механизмы, отражающие неоднородность международного сообщества [Keck, Sikkink, 1999; Adler, 2008]. Одним из таких механизмов является глобальное экономическое управление (ГЭУ), которое как в политическом, так и в экономическом измерении представляет нормативную основу, созданную государственными и негосударственными субъектами для «содействия трансграничной координации и сотрудничеству в предоставлении или обмене товаров, денег, услуг и технических знаний в определенных проблемных областях мировой экономики» [Moschella, Weaver, 2014, p. 4]. Однако этот подход представляется нам крайне недостаточным и ненадежным в контексте «беспорядочной» многосторонности эпохи повторяющихся кризисов и связанной с ними неопределенности в отношении направления, скорости, интенсивности и характера изменений, которые порой оставляют лиц, принимающих решения, беспомощными. Не только структура глобального управления по-прежнему остается не до конца ясной, но и характеристика его институтов размывается изза отсутствия общей точки зрения и консенсуса относительно онтологической формы и природы управления без правительств. Глобальное управление и его институты (нормы, режимы и организации) в политической науке чаще всего определяются как фрагментированное управление, разделенное на межправительственные кластеры сотрудничества с определенным набором моделей поведения [Biermann et al., 2009] и соответствующие им практики, которые контрастируют друг с другом (сотрудничество/ конкуренция; функциональность/дисфункциональность; связь/разъединение). Этот подход к глобальному управлению уходит корнями в теорию режимов, которая видит существенную их особенность в сочетании совпадающих ожиданий и моделей поведения или практик. Сторонники иного подхода к глобальному управлению характеризуют его как систему, которая является полицентричной [Jordan et al., 2018] или сложной [Orsini et al., 2019]. Если первые ставят под сомнение фрагментированную перспективу построения интегрированных режимов и подчеркивают ценность относительно децентрализованных систем, то вторые подчеркивают ценность аутопоэзиса, самовоспроизводящихся и самоподдерживающихся систем, состоящих из многих частей (или зубцов в шестеренке), которые координируют и адаптируют свое поведение без какойлибо всеобъемлющей власти.

Приведенная выше характеристика фрагментированного глобального экономического управления, полная несоответствий и контрастирующих моделей функциональности и дисфункциональности, служит отправной точкой для этой статьи. Задаваясь вопросом, существует ли способ снизить популистские риски для глобального экономического управления в мире после пандемии COVID-19, мы исследуем предложение о создании устойчивого глобального экономического управления «снизу вверх» (на национальном уровне), чтобы тем самым избежать конфликтной фрагментации глобального управления в направлении внутренних и основанных на суверенитете решений. В данном подходе рассматриваются аргументы исследовательского сообщества, которое поддерживает подход «от глобального к национальному», и утверждает, что он может показаться разумным и полезным для демократий, страдающих от некомпенсированных издержек перестройки и перераспределительных эффектов экономической глобализации. Однако обсуждаемые ниже примеры преуменьшения последствий пандемии COVID-19 популистскими лидерами или принятия нелиберального законодательства, препятствующего скоординированным действиям, необходимым для противодействия экономическому и финансовому спаду, могут ослабить эту аргументацию. Эти выводы 
приводят к внедрению решения «от национального к общему», что проявляется в сочетании разумной внутренней политики и расширенного международного сотрудничества.

Прежде всего в статье мы рассмотрим фрагментированность глобального экономического управления и продемонстрируем фрагментарность и нечеткость экономического управления на примере глобального торгового режима. Затем, основываясь на предыдущих исследованиях [Cox, 1994; Rodrik, 2011], проанализируем недостатки гиперглобализации и непоследовательность глобального экономического управления, подчеркнутые некоторыми учеными, в частности Д. Родриком, который указывает на несовместимость глобального экономического управления, воспринимаемого как окончательная основа экономической глобализации, с демократическими странами, имеющими право на защиту своего социального устройства. В этом разделе обсуждается предложение пересмотреть экономическую глобализацию с акцентом на суверенитет, что может дать возможность для проведения четкой национальной политики и смягчить популистское сопротивление глобальному экономическому управлению. Далее мы покажем, как проведение национальной политики, процветающей во времена пандемии COVID-19, может свести на нет преимущества международного институционального сотрудничества вместо того, чтобы стать панацеей от кризиса. В следующем разделе описывается альтернативный способ смягчения противоречий между гиперглобализацией и национальной политикой, предполагающий переход от национального к интегральному управлению. В заключительном разделе резюмируются наблюдения и предлагаются возможности для дальнейшего изучения проблемы.

\section{Размытые горизонты глобального экономического управления}

Структура глобального экономического управления воспринимается как несовершенная идеациональная конструкция. Это связано с тем, что на нее влияют хаотическая многосторонность, фрагментированность, неопределенность и конкурирующие нарративы Востока и Запада, Севера и Юга. В этой конструкции конец истории отрицается повторяющимися кризисами, относительным упадком мировых держав, появлением новых центров экономического влияния и умножением нерешенных проблем. Закончить этот список - безнадежная задача, поскольку на сцену постоянно выходят новые кризисы. Однако нет сомнений в том, что будущее ГЭУ и его архитектуры, по-видимому, определяется необходимостью решения таких проблем, как зашедшие в тупик переговоры в Дохе, всплеск популизма и отказ от «несправедливой» макроэкономической политики. Новая политика, влияющая на работу глобальных цепочек создания стоимости (ГЦС), цифровую торговлю, разрыв глобальной инфраструктуры, нестабильность мировых цен на сырьевые товары и, наконец, разочарование в западных моделях развития поставили под сомнение многие решения, выработанные в эпоху Вашингтонского консенсуса.

На сегодняшний день мы можем выделить как минимум три основных фактора, влияющих на хрупкость глобального экономического управления. Первый - диффузия власти. В нынешней фазе глобализации, которую К. Шваб назвал «четвертой промышленной революцией» (4IR) [Schwab, 2016], новые технологические прорывы (цифровизация, облачные технологии, искусственный интеллект (AI) / робототехника, 3D-печать, 5G и интернет вешей) совпадают с появлением экологических ограничений, возникновением все более многополярного международного порядка и ростом 
неравенства [Deaton, 2013; Held, 2018; Pikkety, Saez, 2003; Pikkety, 2014]. В последней четверти XX в. наблюдается переход власти от развитых стран к развивающимся экономикам, сопровождаемый вовлечением в мировую политику негосударственных акторов, таких как глобальные корпорации [Dicken 2015], гражданское общество и НПО [Scholte, 2011] или рейтинговых агентств [Sinclair, 2005]. Этот процесс приводит к возникновению нескольких проблем: во-первых, к росту числа нетерриториальных организаций, которые могут увеличивать барьеры для международного сотрудничества, что может еще больше способствовать увеличению операционных издержек по заключенным соглашениям; во-вторых, сосредоточению внимания правительств, движимых сокращением затрат, на расширении участия в этих организациях и стремлению к изменению модели управления; в-третьих, к увеличению числа государств, которые считаются важными в различных областях международного сотрудничества, что может снизить шансы примирения интересов и достижения компромисса и сотрудничества.

Второй фактор проблем глобального экономического управления - это процесс, описанный Дж. Розенау [Rosenau, 1997] как «интерместикация» (intermestication), то есть стирание границ между «внутренним» и «внешним», что отражается в последствиях решений, которые, казалось бы, вписываются в логику внутреннего регулирования. Так, например, решения турецкого правительства влияют на увеличение или уменьшение миграционного давления на Европу. Увеличение субсидий для французских фермеров в рамках общей сельскохозяйственной политики оказывает воздействие на выращивание ячменя в Марокко. Американские фирмы, перемещающие производство из Китая, и введение правительством США ограничений на технологии, торговлю и инвестиции из Китая оказывают разрушительное влияние на режим мировой торговли и политику Пекина (Сделано в Китае 2025) [Springborg, 2018]. Последняя представляет собой промышленную политику, направленную на то, чтобы сделать Китай доминирующим в мировом высокотехнологичном производстве, локализовать технологические цепочки поставок и, за счет сочетания государственных субсидий и приобретений интеллектуальной собственности, способствовать тому, чтобы догнать - и, возможно, превзойти - западные страны в передовых отраслях.

Третий фактор - сочетание высокой волатильности институциональных моделей, вовлекающих различных участников глобального управления, с одной стороны, и фрагментации многих областей политики - с другой. Это проявляется в разности международных институтов, которые различаются по форме (организации, режимы, нормы), составу участников (государственному и частному), пространственному охвату (двусторонний, региональный и глобальный) и повестке дня (от узкой до глобальной). Упомянутые выше институциональные модели напоминают точки сетевого равновесия, устанавливаемые при определенных условиях для удовлетворения возникающих потребностей и отражающие баланс сил и интересов. Со временем изменения в условиях, в которых работают международные институты, вызывают несоответствие между их ресурсами и заявленными целями, а также новой средой, в которой они функционируют. В результате они становятся менее эффективными. Возникновение кризисов, таких как «великая изоляция», вызванная распространением пандемии COVID-19, Брекзитом или кризисом суверенного долга 2008 г., приводит к ослаблению некоторых институтов (как показывает пример ЕС или «Глобальной семерки») или исчезновению существующих механизмов (например, Совет экономической взаимопомощи), замене их новыми (например, «Группа двадцати», БРИКС), более приспособленными к изменившимся условиям работы, однако с неясной перспективой [Cooper, Thakur, 2018; Kirton, 2013; Stuenkel, 2015]. Расширение круга акторов ГЭУ привело как к положительным, так и к отрицательным последствиям. С одной стороны, более интенсивная кон- 
куренция между сторонами позволяет эффективно решать основные трансграничные проблемы [Boot et al., 2006]. С другой стороны, постоянно расширяющиеся механизмы регулирования привели к «гонке уступок». Более того, многие субъекты глобального управления часто действуют в одних и тех же сферах, тем самым дублируя деятельность и тратя ресурсы, что де-факто ведет к росту трансакционных издержек (например, Всеобъемлющее и прогрессивное соглашение о Транстихоокеанском партнерстве (CРТPР) и Региональное всеобъемлющее экономическое партнерство (RCEP), которые частично совпадают с точки зрения предмета регулирования и государств-членов).

Упомянутая фрагментация глобального экономического управления особенно заметна в режиме глобальной торговли. Последний можно описать как набор неявных и явных принципов, норм, правил и процедур принятия решений, вокруг которых сходятся ожидания в области международной торговли (подробнее о международных режимах см. [Krasner, 1983]). Основываясь на структуре фрагментации архитектуры управления, предложенной Ф. Бирманном, Ф. Паттбергом, Х. ван Ассельтом и Ф. Зелли, мы можем выделить три формы фрагментации: синергетическую, кооперативную и конфликтную. Основные различия между ними возникают в результате применения набора критериев дифференциации, а именно по степени институциональной интеграции и степени совпадения систем принятия решений; по наличию и степени противоречия норм и, наконец, по набору акторов. Корректировка этой структуры к глобальному уровню анализа позволяет представить глобальный торговый режим с его основным институтом - Всемирной торговой организацией (ВТО).

\begin{tabular}{|c|c|c|c|}
\hline Критерий & Синергетический & Кооперативный & Конфликтный \\
\hline $\begin{array}{l}\text { Поддержка } \\
\text { институциональной } \\
\text { интеграции }\end{array}$ & $\begin{array}{l}\text { Одна базовая } \\
\text { организация тесно } \\
\text { интегрирована } \\
\text { с другими. Все они } \\
\text { поддерживают режим }\end{array}$ & $\begin{array}{l}\text { Базовая организация } \\
\text { или группа со своими } \\
\text { партнерами слабо } \\
\text { интегрированы. } \\
\text { Поддерживаются } \\
\text { основы режима }\end{array}$ & $\begin{array}{l}\text { Различные, } \\
\text { в значительной степени } \\
\text { не связанные между } \\
\text { собой институты } \\
\text { с низким уровнем } \\
\text { интеграции } \\
\text { и поддержки режима }\end{array}$ \\
\hline $\begin{array}{l}\text { Интеграция } \\
\text { принципов, норм, } \\
\text { правил и процедур } \\
\text { принятия решений }\end{array}$ & $\begin{array}{l}\text { Принципы, нормы, } \\
\text { правила и процесс } \\
\text { принятия решений } \\
\text { интегрированы } \\
\text { и контролируются } \\
\text { основными } \\
\text { организациями }\end{array}$ & $\begin{array}{l}\text { Принципы, нормы, } \\
\text { правила и процесс } \\
\text { принятия решений } \\
\text { слабо интегрированы, } \\
\text { не противоречат } \\
\text { друг другу и в боль- } \\
\text { шинстве случаев } \\
\text { контролируются } \\
\text { основной } \\
\text { организацией }\end{array}$ & $\begin{array}{l}\text { Принципы, нормы, } \\
\text { правила и процесс } \\
\text { принятия решений } \\
\text { противоречивы }\end{array}$ \\
\hline Вовлеченность акторов & $\begin{array}{l}\text { Все важные участники } \\
\text { поддерживают одни } \\
\text { и те же институты }\end{array}$ & $\begin{array}{l}\text { Есть инсайдеры, } \\
\text { поддерживающие } \\
\text { основные институты, } \\
\text { и внешние акторы, } \\
\text { которые остаются вне } \\
\text { режима }\end{array}$ & $\begin{array}{l}\text { Основные акторы } \\
\text { поддерживают } \\
\text { различные } \\
\text { институциональные } \\
\text { конструкции }\end{array}$ \\
\hline
\end{tabular}

По первому критерию кооперативной фрагментации во втором и третьем столбцах глобальный торговый режим представляет собой явно конфликтное пространство, в котором ставятся под сомнение принципы, нормы, правила и принятие решений, 
а заинтересованные стороны поддерживают альтернативный институциональный дизайн. Это предположение соответствует сокращающимся возможностям ВТО в роли основной организации по надзору за многосторонней торговой системой. Последняя отлично выполняет четыре функции: действие в качестве кодекса поведения для торговой политики, управление механизмом урегулирования споров, обеспечение многостороннего надзора за торговой политикой и формирование площадки для переговоров, которые стремятся обеспечить прогресс в либерализации торговли [Hoekman, Kostecki, 2001].

Отметим, что основанная на правилах торговая система, символизируемая положением о Наибольшем благоприятствовании торговле, постепенно сменяется дискриминационной либерализацией торговли, основанной на преференциальных торговых соглашениях, которые были инициированы после завершения Уругвайского раунда ГАТТ и ускорились в июне 2006 г., когда переговоры в Дохе были приостановлены [Wróbel, 2017]. Несмотря на возвращение к многосторонним переговорам, эта тенденция продолжилась, что усугубило кризис ВТО как переговорного форума. Согласно данным ВТО, в октябре 2020 г. действовало 306 соглашений о преференциальной торговле, из которых 132 касались товаров, 2 - услуг, а 156 - как товаров, так и услуг. Для сравнения, в 2006 г. таких соглашений было 154 [WTO, 2020]². Тенденция к обходу принципов недискриминационной торговой системы указывает на усталость от переговоров или, по крайней мере, на сомнения в достижимости целей многосторонних переговоров. Члены ВТО отвергают «принцип единого обязательства» [Wolfe, 2009], при этом предпочитая заключать соглашения о преференциальной торговле [Hoekman, Mavroidis, 2015]. Эти формы дискриминационной либерализации торговли позволяют им преодолевать тупики в торговых переговорах. Что еще более важно, они оставляют место для возможного сдвига в сторону рыночной регионализации, что проявляется в более коротких, более локальных и региональных производственно-сбытовых цепочках и увеличивающихся региональных и внутрирегиональных торговых соглашениях, сгруппированных вокруг трех регионов: Азии, Европы и Северной Америки. Это подтверждается данными, опубликованными Азиатским банком развития. Они указывают на высокий объем внутрирегиональной торговли в Азии, который увеличился в среднем с 55,9\% в 2010-2015 гг. до 57,8\% в 2017 г. При этом доля внутререгиональной торговли в ЕС $(63,8 \%)$ значительно превосходит объем внутрирегиональной торговли в Северной Америке (40,7\%) [ADB, 2018, p. 22].

Дискриминационная либерализация торговли, ускоренная мегарегиональными торговыми соглашениями ${ }^{3}$ и зависимостью глобальных производственно-сбытовых цепочек от небольшого количества поставщиков, оказывает мощное, хотя и не всегда благотворное влияние как на страны с формирующимся рынком, так и на страны с развитой экономикой. Ричард Болдуин и Эйити Томиура [Baldwin, Tomiura, 2020] исследовали влияние COVID-19 на торговлю и выявили возможность «заражения цепочек поставок», то есть прямых перебоев, препятствующих производству в основных

${ }^{2}$ Количество действующих соглашений о преференциальной торговле рассчитывается в соответствии с данными ВТО, содержащимися в Информационной системе региональных торговых соглашений (RTA-IS).

${ }^{3}$ Такие как Всеобъемлющее и прогрессивное соглашение о Транстихоокеанском партнерстве (СРТРР), которое развилось из Транстихоокеанского партнерства после выхода США в январе 2017 г., и Всеобъемлющее региональное экономическое партнерство (RCEP), подписанное 15 ноября 2020 г. пятнадцатью странами (Китай, члены Ассоциации государств Юго-Восточной Азии (АСЕАН), а также Японией, Южной Кореей, Австралией, Новой Зеландий, на которые приходится около $30 \%$ мирового ВВП и $30 \%$ населения мира. 
производственных центрах глобальных цепочек стоимости (Япония, Корея, Тайвань, Китай, США и Германия). Размер их ВВП, совокупная доля в мировом производстве и экспорте, а также торговые связи с другими странами способствовали падению объема мировой торговли на 9,2\% в 2020 г. [WTO, 2020]. Экономический кризис был обусловлен не только перебоями в поставках, вызванными рядом мер, направленных на профилактику COVID, которые замедлили производство в основных странах ГЦДС (Глобальных цепочек добавленной стоимости) в Азии, Европе и Северной Америке, но и стал результатом шока спроса и роста экономического протекционизма. Последний фактор может дополнительно быть усилен дискриминационными торговыми соглашениями, которые американский экономист Д. Бхагвати [2008] сравнил с термитами, подрывающими свободную торговлю.

Возможно, риски конфликтной фрагментации, дискриминационного отношения и протекционизма наиболее заметны в отношении технологических тенденций, изменяющих торговлю. На электронную торговлю уже приходится примерно $20 \%$ мировой торговли, и, по прогнозам, к 2025 г. ее доля вырастет до 25\% [Manyika et al., 2018]. Несмотря на огромный потенциал, это виртуальное экономическое пространство не до конца урегулировано. Таким образом, балканизированную [Alves Jr., 2014] цифровую торговлю и, в более широком смысле, цифровую экономику можно определить как неизведанные территории, на которых государства стремятся утверждать свои правила в киберпространстве, находящемся в определенной территориальной юрисдикции, в то время как гигантские глобальные корпорации (GAFAM - Google, Apple, Facebook, Amazon и Microsoft) стремятся бросить вызов любой форме государственного контроля.

Конфликт между государственными и частными стейкхолдерами проистекает из отсутствия международного режима управления интернетом и фундаментального столкновения между двумя представлениями о (цифровом) суверенитете. В настоящее время управление интернетом основано на модели с участием многих заинтересованных сторон, включающей государства, компании, гражданское общество и организации ${ }^{4}$, в которых доминируют США, традиционно воспринимаемые как гарант децентрализованного интернета. Эта система оспаривается основными развивающимися державами «Группы двадцати»: Китай, Россия и Саудовская Аравия провозглашают доктрину «интернет-суверенитета», оформленную как суверенное право регулировать национальный сегмент интернета [Gueham, 2017]. Эти государства вместе с другими странами с развивающейся экономикой, такими как Бразилия, Индия или Индонезия, проводят ограничительную политику, которая ставит под угрозу глобальную цифровую торговлю и услугу передачи данных. Одним из примеров является Китай, который преимущественно наносит ущерб высокотехнологичным американским компаниям, не только ограничивая их цифровое присутствие [Beattie, 2018], но и способствуя «цифровому протекционизму» (например, локализации данных, принудительной передаче исходных кодов, ограничению глобальных потоков коммерческих данных), что является благодатной почвой для дальнейшей фрагментации управления интернетом.

Фрагментация управления интернетом, препятствующая цифровой торговле, сочетается с фундаментальными разногласиями между суверенными государствами и транснациональными корпорациями относительно самой природы суверенитета в киберпространстве. Государства относятся к концепции (национального) суверените-

${ }^{4}$ Интернет-корпорация по присвоению имен и адресов (ICANN) и Инженерной группе Интернета (IETF), отвечающей за сетевые протоколы, а также на Консорциуме World Wide Web (W3C), ориентированном на веб-стандарты. 
та как к форме законной власти, осуществляемой государством на своей территории. Доминирующие высокотехнологичные компании, напротив, настаивают на поствестфальском понимании концепции цифрового суверенитета как формы контролирующей власти, основанной на корпоративном саморегулировании и сопротивлении любым формам законодательного вмешательства. Иными словами, управление интернетом, цифровая экономика и электронная коммерция сдерживаются столкновением поэтического (творческого) и антипоэтического (нормативного) видения киберпространства [Floridi, 2020]. Частные стейкхолдеры предпочитают придерживаться принципа невмешательства и ценности рыночного регулирования путем разработки, производства, продажи и поддержания контроля над цифровыми технологиями, а государства занимают оборонительную позицию, пытаясь регулировать цифровую среду, контролируя данные как ресурсы, исходя из традиционного понимания суверенитета. Их конечная цель - гарантировать и лишить возможности других определять, какое поведение является законным (и ожидаемым), а какое - запрещенным, особенно в таких сферах экономической деятельности, как налогообложение цифровой торговли, регулирование государственных закупок или требование соблюдения национальных законов. Случай государственного контроля над частными заинтересованными сторонами в цифровом пространстве стал очевиден в течение последнего десятилетия, с тех пор как П. Белланжер, генеральный директор французской радиостанции Skyrock, в 2011 г. сделал первую попытку определить цифровой суверенитет как «контроль настоящего и будущего, проявляемый в использовании технологий и компьютерных сетей» [Bellanger, 2011]. Общий регламент ЕC по защите данных (GDPR), внедренный в 2018 г. в качестве регулирующего механизма, не ограничивающего коммерцию и создающего глобальный стандарт защиты конфиденциальности, является примером политизации и секьюритизации цифрового суверенитета. Регламент стал ответом ЕС на риски кибербезопасности, возникающие из-за чрезмерной зависимости от китайской инфраструктуры $5 \mathrm{G}$ и контроля GAFAM над данными онлайн-пользователей. Это было подтверждено во время экономического кризиса, вызванного последствиями пандемии COVID-19. Tехнологические решения крупнейших компаний (таких как Apple или Microsoft) могут фрустрировать государства, которые способны разрабатывать собственные подходы (например, “Stop COVID” во Франции), тем самым подпитывая стремление к усилению цифрового суверенитета. Таким образом, в посткоронавирусном мире, где роль технологий будет возрастать, одной из основных задач для политиков станет поиск правильного баланса между контролем и правом на конфиденциальность.

\section{От глобального к национальному управлению}

Нечеткость глобального экономического управления, его фрагментация и дисфункциональность побуждают ученых задуматься о последствиях несовместимости экономической системы, воспринимаемой в качестве окончательной, с демократиями, которые имеют право защищать свою социальную жизнь и договоренности. Они понимают, что глобальное (экономическое) управление находится под шквальным огнем нового vox populi, подчеркивающего противодействие либеральному международному порядку. Этот новый популизм чаще всего интерпретируется как идеология и характеризуется моральным и манихейским различием между «народом» и «другим». Данный подход строится на убеждении в том, что политика заключается в уважении суверенитета любой ценой [Mudde, 2004; Mudde, Rovira Kaltwasser, 2018]. Как отмечают Мадди и Кальтвассер, популизм с сильной антиэлитарной направленностью может привести к маргинализации определенных групп общества и ослаблению политических институтов, 
что, в свою очередь, приведет к подрыву прав и механизмов защиты меньшинств. В том же ключе Д. Родрик [Rodrik, 2018] предполагает, что ответная реакция популистов на политические элиты и глобализацию может усилить формирование новых линий разлома, которые будут подрывать легитимность или власть политических институтов, а также возможность поиска компромиссов. По его мнению, популисты могут атаковать либеральную демократию и установившийся международный порядок по двум направлениям. Первое заключается в том, что популистские лидеры могут мобилизовать «людей» по этнонациональному / культурному принципу, опираясь на шок от потоков мигрантов и беженцев [Ibid., p. 2]. Примером этого шокового эффекта является политическая практика партии «Венгерский гражданский союз» (ФИДЕС) в Венгрии [Krekó et al., 2018]. Я.-Вернер Мюллер [Muller, 2016] разделяет эту точку зрения и утверждает, что популистам может помочь «культурная война», развязанная в определенной стране. Это позволит сторонникам популистов подтвердить свою веру в то, что именно они «настоящее люди», с должным набором ценностей. Второе направление - мобилизация сторонников по принципу дохода / социального класса. В данном случае шок от глобализации коренится в трансформации международной торговли и финансов, что наиболее ощутимо для более бедных социальных слоев западных стран [Pierce, Schott, 2012; Autor et al., 2013]. Широко распространено мнение о том, что последствия глобализации, включая несправедливую международную торговлю, мобильность капитала и повторяющиеся экономические и финансовые кризисы, могут привести к росту безработицы, снижению заработной платы, замедлению темпов роста и депривации. В свою очередь, последнее ведет к растущему недовольству и радикализации [Funke et al., 2016] $]^{5}$.

Экономические источники негодования и противодействие популистов либеральной экономике и глобализации заметны в конкретных программах, рассматривающих глобализацию как фактор ослабления национальных государств, который подрывает суверенитет и демократию и вводит в заблуждение «народ» пустыми обещаниями. Д. Родрик, известный своим критическим подходом к более глубокой экономической интеграции, называет глобальное управление «ложным обещанием» [Rodrik, 2017, p. 206], утверждая, что гражданское общество является национальным, как и государства, и что мировую экономику следует «лечить» на внутреннем уровне. Родрик выводит рост популизма из перераспределительного эффекта экономической глобализации, при этом конкретизируя вопрос о неравенстве и суверенитете, который ограничен «темными призраками» глобализации, представленными транснациональной бюрократической и деловой элитой, действующей над главами государств. Его размышления напоминают идеи школы критической теории международных отношений [Moolakkattu, 2009]. Они сконцентрированы на появлении новых центров управления, которые сочетают в себе транснациональное регулирование, государственно-частные режимы, формы частного управления и саморегулирования, составляя новую форму

${ }^{5}$ Не для всех социологов экономические обстоятельства являются ключевой переменной, объясняющей появление международной волны популистской политики. Р. Итуэлл и М. Гудвин вместо того, чтобы исследовать финансовый кризис или различия в социально-экономическом статусе в качестве основных причин популизма, изучают политику идентичности и подчеркивают важность «четырех D», которые усиливают национальный популизм: недоверие (или низкое доверие) к политическому истеблишменту; «разрушение» давно укоренившихся представлений об общей идентичности, которые постепенно заменяются моделями неограниченной глобализации; «депривация», порождаемая растущим неравенством и углублением разногласий между «имущими» и «неимущими»; «дислокация» между личной идентичностью и конкретными политическими партиями или брендами [Eatwell, Goodwin, 2018]. 
глобального государственного устройства [Coх, 1994]. Р. Кокс назвал эти новые структуры «глобальной туманностью». Аналогичное мнение было высказано С. Стрэндж, исследователем международной политической экономии, которая заметила, что как формальные, так и неформальные организации, обладающие значительной автономией и располагающие активами, могут играть роль ключевых акторов и генераторов идей. Такие идеи впоследствии распространяются как ментальные конструкции высшими эшелонами государственных служащих, руководителями международного бизнеса, специалистами и экспертами, заседающими в рабочих группах, встречающимися на конференциях и формирующих эпистемологические сообщества [Strange, 1996, p. 62].

И Р. Кокс, и Д. Родрик в своих общих взглядах на экономическую глобализацию точно указывают на риск ее расширения до социально неприемлемых пределов. Этот феномен получил название «гиперлиберализм» [Cox, Sinclair, 1996], или «гиперглобализация» [Rodrik, 2011]. Кокс рассматривает гиперлиберализм как фундаментальное преобразование неолиберальной формы государства в его чрезмерную, гиперлиберальную версию, материализовавшуюся в результате отказа от договора, заключенного с капиталом и рабочей силой во время послевоенного экономического бума. Подготовленный и внедренный коллективными усилиями правительства и бизнеса, или альянса «глобальная туманность», он исключает решения корпоративного типа, такие как согласованные зарплаты и ценовая политика, и уводит на задний план обязательства в отношении занятости и социального обеспечения. Реструктуризация производства приводит к усилению сегментации и разделения внутри рабочего класса (например, между рабочими-мигрантами и местной рабочей силой) и противопоставлению «имущих» и «неимущих». Это также значительно расширяет список обездоленных и исключенных групп, испытывающих трудности, лишения, от безработных как прямых получателей социальных пособий, через фермеров и малые предприятия до рабочих в чувствительных отраслях, таких как текстильная, автомобильная, сталелитейная или судостроительная. Социально-экономические популисты используют капитал социальной неудовлетворенности, накопленной за многие годы, и политически мобилизуют бесправное большинство против небольшого большинства (или элиты) и их гиперлиберальной политики [Coх, 1996]. Это противостояние между исключенными и включенными группами особенно заметно в западных обществах. Оно проходит по линии доход/социальный класс, как показал американский политолог Я. Бреммер [Bremmer, 2018]. Он описывает ситуацию, в которой процесс экономической либерализации в США способствует росту ВВП и среднего дохода национальных экономик, в то же время приводя к неравномерному распределению благ. По мере увеличения разницы в достатке это распределение рассматривается как все более и более несправедливое. Если мы добавим к этому всевозможные компенсации, нечеткие системы вознаграждения в банках и государственных предприятиях (которые обходят правила о чрезмерных зарплатах), необузданное желание представителей политического класса увеличить свое вознаграждение, а также премии, которые более чем в 10 раз превышают среднюю заработную плату, неудивительно, что движение против истеблишмента опирается на большее распределение богатства в своих избирательных кампаниях [King, 2017].

Через двадцать лет после того, как Р. Кокс назвал гиперлиберализм «потенциальной» новой политической ортодоксией, Д. Родрик рисует картину гиперглобализации как реальной «программы экономической либерализации и глубокой интеграции» [Rodrik, 2011, p. xvii], и как модели послевоенной глобализации: «... торговые соглашения вышли за пределы их традиционной сосредоточенности на импортных ограничениях и стали затрагивать внутреннюю политику государств, был снят контроль над 
международными рынками капитала, и развивающиеся страны оказались под сильным давлением, заставившим их открыть свои рынки для внешней торговли и инвестиций. По сути, экономическая глобализация стала самоцелью» [Rodrik, 2011, p. xvii].

По мнению Родрика, «гиперглобализация» является ключом к пониманию трех итераций политических режимов («золотая смирительная рубашка», «бреттон-вудский компромисс» и «режим глобального управления» ${ }^{6}$, которые характеризуются натянутыми отношениями между глобализацией и национальной демократией. Родрик [Ibid.] в так называемой «политической трилемме глобализации» утверждает, что существует неизбежный конфликт между глобализацией, национальным государством и демократической политикой. Режим «золотая смирительная рубашка» несовместим с демократической политикой, «бреттон-вудский компромисс» несовместим с гиперглобализацией, а «режим глобального управления» несовместим с национальным государством. Каждый из политических режимов может иметь две, но не все три характеристики, поэтому странам необходимо ограничивать демократию, ограничивать глобализацию или глобализировать демократию.

Наблюдая за несовместимостью этой высшей формы экономической глобализации с демократиями, которые имеют право защищать свое социальное устройство, Родрик [Rodrik, 2018, p. 38] рекомендует «сместить баланс по трем направлениям: от капитала и бизнеса к труду и остальному обществу, от глобального управления к национальному управлению и от сфер с относительно небольшой общей экономической выгодой к тем, где она велика». Однако фундаментальная проблема такого решения популистского вызова заключается в том, что восстановление международной экономики с акцентом на суверенитет может привести к разрушению преимуществ международного институционального сотрудничества, достигнутых к настоящему времени [Hoekman, Nelson, 2018]. Предоставление слишком большого пространства для маневра правительствам, которые свободны от ограничений, налагаемых международными организациями, и которые могут свободно проводить политику, позволяющую достичь целей национального экономического развития, может изменить позиции ключевых агентов и тем самым привести к структурным изменениям в глобальном экономическом управлении. Таким образом, это может усилить тренд на антиглобализацию, ускорить откат от либерализации и обострить отношение ко всему иностранному: мигрантам, компаниям или инвестициям, которые будут восприниматься как угроза национальной безопасности. Более того, неограниченное национальное управление может работать как усилитель внешних угроз, таких как торговые потрясения, экономические и финансовые кризисы, и служить оправданием для отката от механизмов компенсаций (социального обеспечения / сетей социальной защиты) в результате проведения политики жесткой экономии.

Угрозы, проистекающие из проведения национальной политики, отделенной от более широкого международного сотрудничества, подтвердились во время кризиса COVID-19, который продемонстрировал, как различные либеральные и нелиберальные демократии, контролируемые популистскими лидерами, освоили использование национального нарратива и взяли на себя чрезмерные и чрезвычайные полномочия,

${ }^{6}$ Первый из политических режимов можно определить как золотой стандарт ХІХ в., или Режим золотой смирительной рубашки. Второй режим соответствует бреттон-вудскому режиму середины XX в., когда группа демократических национальных государств ограничила глобализацию посредством политического контроля над международной торговлей (тарифы) и финансами (например, регулируемые обменные курсы). Третий политический режим - это гиперглобализация как программа экономической либерализации и глубокой интеграции, когда национальное государство заменяется глобальным управлением. 
чтобы расправиться с политическими оппонентами или СМИ, увеличить базу сторонников и, наконец, подорвать скоординированные действия, необходимые для противодействия экономическим последствиям пандемии [He, Chen, 2020]. Здесь мы должны отметить, что популизм как идеология, для которой характерно различие между «народом» и «другим» и убежденность в том, что политика заключается в уважении суверенитета любой ценой, влияет на дальнейшую позицию лидеров стран. Социально-экономические популисты (такие как Л. Обрадор (Мексика), Д. Ортега (Никарагуа) или Н. Мадуро (Венесуэла) обращаются к менее образованным слоям общества («истинным людям») и выступают против как отечественной бизнес-элиты, так и международных капиталистов / финансовых организаций («других»). Культурные популисты (Ж. Болсонару (Бразилия), Д. Трамп (США), В. Орбан (Венгрия), Н. Моди (Индия), Р. Дутерте (Филиппины) и Р.Т. Эрдоган (Турция) способствуют культурным конфликтам, противопоставляя коренные народы, этнические/религиозные группы («истинные люди») этническим / религиозным меньшинствам и культурным элитам («другие»).

Пандемия COVID-19, в частности, выявила социально-экономические, культурные и политические разногласия между популистами и глобалистами, которые напрямую сказались на борьбе с внутренней эпидемией, отношении к основным организациям режима глобального управления здравоохранением и на международном сотрудничестве против последствий пандемии (оказание помощи, раскрытие данных, совместные исследования вакцин). Культурные и социально-экономические популистские лидеры, преуменьшавшие последствия COVID-19 (Трамп, Болсонару и Обрадор), были склонны не замечать серьезность пандемии, чтобы сохранить экономику и занятость, и поэтому всячески заверяли базовых избирателей в том, что «пандемия... не опасна» [Linthicum, 2020]. Как следствие, такая политика, проводимая президентами США и Бразилии, продвигающих масштабные программы экономического восстановления [Mason, Holland, 2020], вместо сосредоточения внимания на научно обоснованных мерах профилактики и контроля после ранних стадий пандемии, привела к резкому росту числа случаев инфекции и смертей, и теперь эти страны занимают 1-е и 3-е места соответственно в мире по количеству смертей [Worldometer, 2020] (на момент написания статьи. - Примеч. пер.).

Культурных и социально-экономических популистов сближает преуменьшение опасности пандемии или использование нелиберальных ответов на COVID-19, что в некоторых случаях стирает вышеупомянутое различие, объединяя цели сдерживания политического «другого» и обвинения экономических / финансовых элит в насущных проблемах. Одним из примеров является нелиберальная реакция на COVID-19 в Центральной Европе, которую продемонстрировал премьер-министр Венгрии В. Орбан. Он использовал культурную и социально-экономическую идеологию для переориентации с европейского подхода к политике и экономике на собственный суверенитет. Для Орбана, как прежде всего культурного популиста, первая волна пандемии создала возможность использовать чрезвычайное законодательство в целях повышения национальной безопасности. Законопроект, принятый в венгерском парламенте в марте 2020 г., нивелирует разделение властей и предусматривает тюремное заключение сроком до пяти лет за публикацию ложных или искаженных фактов, которые могут встревожить или взволновать общественность [Szekeres, 2020]. Несмотря на то что венгерские законодатели в июне проголосовали за отмену чрезвычайных полномочий, различные НПО заявили, что голосование за их снятие было фикцией. При этом Орбан продолжил преследовать независимых журналистов и политических оппонентов [ВВС, 2020]. Взаимосвязь культурного и социально-экономического популизма Орбана стала заметна в результате внешнего идеологического давления после 
столкновения между Венгрией и ЕС из-за европейского бюджета в размере 1,82 трлн евро и пакета мер по восстановлению, который включал блокирование переговоров по коллективной задолженности․ Долгое время Венгрия препятствовала доработке пакета из-за своей оппозиции новому механизму, который позволил бы ЕС урезать финансирование странам-членам, признанным нарушающими принцип верховенства закона. В этом случае фундаментальное разногласие между идеями национального суверенитета и объединенным суверенитетом ЕС, принявшее форму личных претензий между премьер-министром Венгрии и вице-президентом ЕС В. Йоуровой [Bayer, 2020], могло иметь серьезные последствия для регионального и глобального развития экономического управления. Блокировка фонда ЕС для восстановления после коронавируса в размере 750 млрд евро в связи с соблюдением верховенства закона может значительно усилить «заражение цепочки поставок» в глобальном масштабе [Baldwin, Weder di Mauro, 2020]. Негативные последствия этого могут привести к потере работы, что лишь в некоторой степени компенсируется мерами поддержки доходов, вводимыми отдельными правительствами (гарантированные доходы, налоговые льготы и т.д.). Таким образом, мы можем сделать два вывода. Во-первых, популистский лидер даже небольшой страны может, учитывая конкретный международный или региональный контекст, оказывать мощное идеологическое давление, тем самым препятствуя экономическому сообществу в реализации долгосрочных программ выхода из кризиса. Во-вторых, идеи Родрика о перераспределении баланса от глобального управления к национальному могут быть неоптимальным решением в условиях взлета популизма.

\section{От национального к интегрированному управлению}

Политический и экономический анализ, проведенный выше, показал, что от глобализации и глобального экономического управления трудно отказаться, однако альтернатива пересмотра политики и экономики по национальному и суверенному признаку является по крайней мере спорной. Возможно, наиболее реальным решением этой дихотомии мог бы стать поиск золотой середины между гиперглобализацией и национальным подходом. В данной статье этот подход мы назвали «интегральным экономическим управлением (ИЭУ)»․ Он берет начало из теории интегрального управления и сочетает в себе различные элементы жесткого и мягкого управления для достижения часто противоположных целей: стабильности вкупе с инновационным развитием [Drucker, 1992; Templar, 2011]. Жесткое управление подчеркивает технические и эко-

\footnotetext{
${ }^{7}$ После длительных переговоров в декабре 2020 г. лидеры ЕС достигли консенсуса по бюджетному пакету и механизму верховенства закона, его обусловливающему.

${ }^{8}$ Идея среднего курса между гиперглобализацией и национальной политикой уже много лет находится в центре дискуссий. Примечательно, что существует значительное сообщество ученых, изучающих «глобальные региональные» сдвиги в нынешней структуре глобального экономического управления. Они указывают на парадокс, с которым сталкивается глобальное управление, а именно, что политическая власть для решения глобальных проблем и мобилизации необходимых ресурсов приписывается национальному уровню, в то время как источник и масштаб проблем, и потенциальные решения для них являются транснациональными или глобальными. Если «вся политика носит региональный характер», как они утверждают, глобальное управление должно быть усилено за счет региональной интеграции, возможно, под эгидой новых сил, развивающихся региональных институциональных структур, таких как Большая Евразия, ВРЭП, BRI, ASEAN +, MEРКОСУР и др. Хотя этот подход ценен при обсуждении путей расширения государственного сотрудничества в области торговли, финансов или безопасности, он заблокирован проблемами коллективных действий, игнорирует неэлитарные вопросы продвижения демократии, безопасности человека, надлежащего управления и совершенствования государственной политики.
} 
номические системы организации и делает упор на рационализацию работы, максимизацию производительности и минимизацию потребления ресурсов в организации, а мягкое управление, напротив, склоняется к развитию организационной культуры, основанной на гибкой, сетевой и эффективной системе формирования межличностных связей. Наряду с жесткими и мягкими методами управления существуют жесткие и мягкие проблемы [Ackoff, 1993]. Сложные организационные проблемы выражаются в трудностях формулирования четких целей и задач, использования соответствующих данных или создания механизмов контроля. Их мягкие эквиваленты связаны с препятствиями на пути к достижению соглашения или возможностью переговоров. Последняя рассматривается как многомерная структура, в которой власть рассредоточена, оценка ситуации и достижение целей затруднены, учитывая сосуществование консенсуса и конфликта.

Подобно управленческим инновациям в организации, ИЭУ рассматривает глобальное управление как фрагментированную структуру, полную жестких и мягких проблем. Хотя этот подход согласуется с утверждениями Родрика о том, что гражданское общество является национальным, как и национальные государства, и большинство неудач глобального экономического управления происходит из внутренних проблем, он подчеркивает необходимость поиска решений не только на национальном уровне. Данный подход требует сочетания жестких (разумная внутренняя политика) и мягких (усиление международного сотрудничества) элементов компромиссного решения.

\section{Разумная внутренняя политика}

Первый компонент ИЭУ выражается в повышении качества внутренней политики, выявлении передовой практики регулирования и поощрении обучения, что, в свою очередь, может уменьшить бремя, возлагаемое на внутреннюю политику и повлиять на восприятие глобализации вместо того, чтобы указывать на нее как на причину внутренних проблем. Достижение этих целей зависит от развития международного сотрудничества в области глобального управления, которое выходит далеко за рамки внешней торговли и инвестиций. Хорошим примером такого союза внутренней политики с международным сотрудничеством является Республика Южная Корея. С 1960-х годов ее экономика росла поразительными темпами [Chung, 2007], в итоге Южная Корея стала «державой средней руки» [Jordaan, 2003]. Южная Корея эффективно среагировала на COVID-19, поскольку быстро сгладила эпидемическую кривую, не закрывая предприятия, опираясь лишь на временные меры. Положительные эффекты сдерживания пандемии стали возможны благодаря выявлению передовых методов регулирования и извлечению уроков из ошибочных ответных мер на вспышку ближневосточного респираторного синдрома (MERS) в 2015 г., что побудило правительство Южной Кореи провести несколько реформ в области здравоохранения страны [Oh, 2020]. В отличие от других средних держав, контролируемых культурными и социально-экономическими популистскими лидерами, как Бразилия и Мексика, эффективная система здравоохранения Южной Кореи основана на сочетании обнаружения (инновационные высокопроизводительные скрининговые клиники и государственно-частное сотрудничество для обеспечения достаточного количества тестов), сдерживания (изоляция инфицированных людей, дополненная продвинутой системой отслеживания контактов, поддерживаемых различными базами данных) и лечения (увеличение количества медицинского персонала, строительство временных больниц и централизованная закупка средств индивидуальной защиты) [Our World in Data, 2020]. 
Успех Кореи в сдерживании коронавируса во многом стал возможен благодаря использованию личных данных и во многом зависел от ее способности быстро расширять масштабы технологических решений. Последнее, по-видимому, имеет решающее значение не только с точки зрения национальной системы здравоохранения, но и для глобального экономического управления после COVID-19. Технологические инновации и выбор государственной политики влияют на революцию в глобальной цепочке создания стоимости, которая началась в конце $\mathrm{XX}$ в. и заметно изменила разделение власти в мире. Р. Болдуин назвал это «вторым разукрупнением», поскольку ИКТ позволили практически бесплатно передать ноу-хау из наиболее развитых стран Большой семерки в развивающиеся страны [Deba, Baldwin, 2016]. Технологический поток определялся международными производственными сетями, а не просто национальными границами. Пример Южной Кореи, Китая и Японии - стран, которые вышли за рамки соответствующей национальной политики, внедрили эффективные, научно обоснованные меры профилактики и контроля и активно участвовали в международном сотрудничестве по борьбе с болезнями (например, предоставляя финансовую поддержку для ВО3), показал, что в таких государствах намного лучше обстоят дела с точки зрения количества случаев заболевания и показателей смертности [Worldometer, 2020].

\section{Расширенное международное сотрудничество}

Сочетание разумной внутренней политики и международного сотрудничества в здравоохранении может послужить полезным уроком для тех, кто реформирует глобальное экономическое управление. ГУЭ представляет собой группу акторов, вовлеченных в несколько фрагментированных и неэффективных международных режимов, которые со временем приняли форму конфликтных пространств, где ставятся под сомнение принципы, нормы, правила и процесс принятия решений, а различные заинтересованные стороны поддерживают альтернативные институциональные конструкции. Перспективы целостного экономического управления основаны на том, чтобы избежать фрагментации режимов и неэффективности их основных организаций, сосредоточив внимание на «Группе двадцати» для более гибкого, эффективного, прозрачного и комплексного ответа на коллективные проблемы [Kirton, 2013].

Главный аргумент, оправдывающий роль «Группы двадцати» как гаранта целостного экономического управления, - это высокая гибкость этого неформального «главного форума международного экономического сотрудничества» [G20, 2009] и его опыт в принятии на себя роли главного ответчика на различные потребности, которые были поставлены членами международного сообщества. Высшей точкой для «Группы двадцати» стали 2008-2009 гг, а именно три прорывных саммита: в Вашингтоне (2008 г.), Лондоне (2009 г.) и Питтсбурге (2009 г.). Они придали этому форуму импульс и укрепили его имидж в качестве центра управления разнообразием институциональных узлов. Встреча лидеров, проведенная в самом сердце Соединенных Штатов, сместила баланс от «Группы семи», которая больше ассоциировалась с «говорильней» [Lesage, 2007, p. 107; Debaere, Orbie, 2013, p. 311-323], в сторону «Группы двадцати», которую лидеры воспринимали скорее как «руководящий комитет» или «форум за круглым столом», имеющий глобальный состав [Cooper, Thakur, 2013, p. 16]. В этом контексте на саммите в Вашингтоне были определены ключевые действия по смягчению последствий финансового и экономического кризиса и был начат процесс их применения. Второй саммит «Группы двадцати» в Лондоне достиг существенных результатов в преодолении экономического и финансового кризиса, согласившись утроить финансовые ресурсы (до 750 млрд долл.) в целях укрепления МВФ и создания более устойчивого финансового 
режима, путем согласования новых распределений специальных прав заимствования и поддержки торговли [Hajnal, 2014]. Во время третьего саммита «Группы двадцати» в Питтсбурге лидеры не только провозгласили «Группу двадцати» главным форумом для международного экономического сотрудничества, но и запустили так называемое «Рамочное соглашение по обеспечению уверенного, устойчивого и сбалансированного экономического роста» и сигнализировали о расширении повестки дня «Группы двадцати» на несколько областей устойчивого развития (энергетика и климат), а также на большую экономическую инклюзивность [G20, 2009]. Последнее было подтверждено на саммите «Группы двадцати» в Сеуле (2010 г.) в смелой программе развития, известной как «Сеульский консенсус в области развития» [G20, 2010]. Десять лет спустя, во время внеочередного саммита лидеров «Группы двадцати», организованного Саудовской Аравией 26 марта 2020 г. [G20, 2020] и нацеленного на борьбу с последствиями COVID-19, лидеры «двадцатки» выступили с заявлением, которое усилило ее антикризисный характер, согласившись на вливание более 5 трлн долл. США в мировую экономику в рамках целевой фискальной политики и экономических мер для гарантий противодействия социальным, экономическим и финансовым последствиям пандемии, и (2) координацию глобальных ответных мер по линии международных организаций, таких как ВОЗ, МВФ, ГВБ, МОТ, ОЭСР, многосторонних и региональных банков развития для предоставления финансовой помощи и контроля занятости.

На сегодняшний день гибкость «Группы двадцати» была неоднократно подтверждена не только в случае глобального кризиса, но и в случае серьезных глобальных экономических и социальных проблем, которые были должным образом рассмотрены в ее повестке дня. Одним из примеров международного сотрудничества, которое дает возможность снизить акцент на внутренней политике, является план «Группы двадцати» по устранению разрыва в глобальной инфраструктуре. Дефицит инвестиций в инфраструктуру можно определить как разницу между инвестиционными потребностями страны и суммой, которая может быть потрачена при текущих тенденциях. Согласно данным, опубликованным в Global Infrastructure Outlook в июле 2017 г. и охватывающим пятьдесят стран и семь секторов экономики (энергетика, телекоммуникации, транспорт, аэропорты, железные дороги, дороги и порты), глобальные инвестиции в инфраструктуру должны составить 94 трлн долл. в период с 2016 по 2040 г. Чтобы удовлетворить эту потребность, миру придется увеличить долю ВВП, выделяемую на инфраструктуру, до 3,5\% по сравнению с 3,0\%, которые расходуются сейчас [Global Infrastructure Hub, 2017]. Международное сотрудничество для восполнения финансового дефицита в странах с развитой экономикой стало решающим по двум причинам. Во-первых, инфраструктура эпохи, начавшейся после Второй мировой войны, подходит к концу срока эксплуатации и нуждается в замене. В то же время государственные бюджеты расходуются на другие сферы, в то время как инвестиции в инфраструктуру отходят на второй план из-за глобального финансового кризиса. Пандемия COVID-19 породила Великую изоляцию, что помогло сдержать вирус и спасти жизни, но спровоцировало худшую рецессию со времен Великой депрессии. Вторая причина заключается в том, что инвестирование в инфраструктуру дает возможности для создания рабочих мест, ведет к более быстрому возобновлению экономической активности и ослабляет последствия политики гиперглобализма. Обезвредить бомбу социального негодования, заметную в западных обществах, можно благодаря усилиям «Группы двадцати», которая с 1998 по 2008 г. стала высшим форумом, на который возложена задача создания соответствующего механизма глобального управления и реагирования на различные потребности международного сообщества [Cooper, Thakur, 2013]. В 2018 г. во время аргентинского председательства в «Группе двадцати» был представлен план по 
восполнению предполагаемых финансовых инвестиций в инфраструктуру [G20, 2018]. Решение опиралось на три основания: (1) использование государственных финансов (например, налогов, пенсий, платы за услуги инфраструктуры) для привлечения или стимулирования инвестиций частного сектора, особенно долгосрочных институциональных инвестиций; (2) твердую приверженность созданию цепочки «приемлемых для банков» проектов с упором на мегапроекты, которые финансируются и управляются через государственно-частное партнерство (ГЧП); и (3) совершенствование механизмов для быстрого воспроизведения ГЧП, что может способствовать уменьшению бремени, возлагаемого на внутреннюю политику (например, в секторе здравоохранения после COVID-19), и признание ценности более глубокого международного сотрудничества для ослабления популистских настроений.

\section{Заключение}

Представленный политический и экономический анализ до сих пор был сосредоточен на обсуждении размытого и фрагментированного глобального экономического управления как основы для экономической глобализации. Мы пришли к выводу о несовместимости глобального управления и глобализации с национализмом и популизмом, рассматривая глобализацию как обширную идеологию, которая наносит ущерб национальным государствам, подрывает суверенитет и демократию и вводит в заблуждение «народ» ложными обещаниями. Вместе с тем было пересмотрено предложение о создании устойчивого глобального экономического управления снизу (на национальном уровне) для избегания конфликтной фрагментации глобального управления в направлении основанных на суверенитете решений. В то время как подход «от глобального к национальному» может показаться разумным и полезным для демократий, которых преследуют некомпенсированные издержки адаптации и перераспределительные эффекты экономической глобализации, примеры преуменьшения последствий пандемии COVID-19 популистскими лидерами или принятия нелиберального законодательства, препятствующего осуществлению скоординированных действий, необходимых для противодействия экономическому и финансовому спаду, могут ослабить эту аргументацию.

Если нельзя отказаться от глобализации и глобального экономического управления, а альтернатива пересмотра политики и экономики в соответствии с национальными и суверенными принципами является спорной, возможно, наиболее реальным решением будет выбор золотой середины между гиперглобализацией и национальной политикой. Данный переход «от национального к интегральному», за счет сочетания разумной внутренней политики и расширенного международного сотрудничества мы назвали «интегральным экономическим управлением». С одной стороны, при таком подходе стоит повышать качество внутренней политики путем выявления передовой практики регулирования и поощрения обучения, что будет смягчать внутреннюю напряженность. С другой стороны, необходимо расширять международное сотрудничество в областях глобального управления для преодоления фрагментированности и неэффективности международных режимов. Вместо не справляющихся со своими задачами глобальных организаций (примером которых является ВТО) целостность ИЭУ требует переноса внимания на «Группу двадцати», способную дать гибкий, эффективный, прозрачный и комплексный ответ на коллективные проблемы по всему спектру глобального управления, а также стать предвестником более глубокого международного сотрудничества, которое могло бы стать частью ответа на растущий популизм после COVID-19. 
Формат статьи не позволяет нам дальше вести эту дискуссию. Мы ограничились лишь базовыми характеристиками «Группы двадцати», выступающей как центр целостного экономического управления, и прояснили роль этого объединения как в борьбе с кризисами, так и в реагировании на различные глобальные вызовы. Продолжение исследования должно быть сосредоточено на влиянии внутренних и внешних факторов на повестку дня «Группы двадцати», анализе соблюдения лидерами «Группы двадцати» своих коллективных обязательств и, наконец, изучении того, как и в какой степени ориентированы на практику механизмы управления, которые построены на взаимосвязи между (1) «Группой двадцати», действующей как центр многоуровневого сотрудничества, (2) международными организациями, предлагающими экспертные знания в конкретных проблемных областях, и (3) государственными чиновниками, ответственными за конкретные вопросы, могут способствовать расширению международного сотрудничества и стимулировать переход от глобального к интегральному экономическому управлению.

\section{Источники}

Abdeneur A. (2016). Rising Powers and International Security: the BRICS and the Syrian Conflict // Rising Powers Quarterly. Vol. 1. No. 1. Р. 109-133. Режим доступа: http://risingpowersproject.com/wp-content/ up-loads/2016/10/vol1.1.Adriana-Erthal-Abdenur.pdf (дата обращения: 28.04.2021).

Arnold K.M. et al. (2011). Facing the Challenges. Three Scenarios for Global Economic Governance in 2020. Berlin: GG2020 Economic Governance Working Group.

Autor D., Dorn D., Hanson G. (2016). The China Shock: Learning from Labor Market Adjustment to Large Changes in Trade // Annual Review of Economics. Vol. 8. P. 205-240.

Baldwin D.A. (2002). Power and international relations // The Handbook of International Relations / W. Carlsnaes, T. Risse, B.A. Simmons (eds). Thousand Oaks: Sage Press.

Barnett M.N., Duvall R. (2005). Power in International Politics. International Organization. Vol. 59. No. 1. P. 39-75.

Barnett M.N., Duvall R. (2018). Organization and the Diffusion of Power. International Organization and Global Governance / T.G. Weiss, R. Wilkinson (eds). N. Y.: Routledge.

Beiser F.C. (2016). Weltschmerz. Pessimism in German Philosophy, 1860-1900. Oxford: Oxford University Press.

Bertelsmann-Scott T. et al. The New Development Bank: Moving the BRICS from an Acronym to an Institution. South African Institute of International Affairs (SAIIA), Occasional Paper 233.

Bousquet A., Curtis S. (2011). Beyond Models and Metaphors: Complexity Theory, Systems Thinking and International Relations // Cambridge Review of International Affairs. Vol. 24. No. 1. P. 43-62.

BRICS (2014). Agreement on the New Development Bank. Fortaleza, Brazil. July 15. Режим доступа: http:// www. brics.utoronto.ca/docs/140715-bank.html (дата обращения: 28.04.2021).

Bucher B. (2014). Acting Abstractions: Metaphors, Narrative Structures, and the Eclipse of Agency // European Journal of International Relations. Vol. 20. No. 3. P. 742-765.

Burgoon B. (2009). Globalization and Backlash: Polayni’s Revenge? // Review of International Political Economy. Vol. 16. No. 2. P. $145-177$.

Cienki A., Yanow D. (2013). Why Metaphor and other Tropes? Linguistic Approaches to Analysing Policies and the Political // Journal of International Relations and Development. Vol. 16. No. 2. P. 167-176.

Cohen R.L., Greenberg J. (1982). The Justice Concept in Social Psychology. N. Y.: Academic Press.

Cooper A.F., Farooq A.B. (2016). The Role of China and India in the G20 and BRICS: Commonalities or Competitive Behaviour? // Journal of Current Chinese Affairs. Vol. 45. No. 3. P. 73-106. 
Cooper A.F., Thakur R. (2018). The BRICS in the Evolving Architecture of Global Governance. International Organization and Global Governance / T.G. Weiss, R. Wilkinson (eds). N. Y.: Routledge. 2nd ed.

Cox M. (2017). The Rise of Populism and the Crisis of Globalisation: Brexit, Trump and Beyond // Irish Studies in International Affairs. Vol. 28. P. 9-17.

Deutsch M. (1985). Distributive Justice: A Socio-Psychological Perspective. New Haven: Yale University Press.

Frieden J. (2017). The Politics of the Globalization Backlash: Sources and Implications. Repared for Presentation at the Annual Meetings of the American Economics Association, Panel on "Making Globalization Inclusive", 6 January.

Guzzini S. (2005). A Concept of Power: A Constructivist Analysis // Millennium. Vol. 33. No. 3. P. 495-521.

Haas R. (2010). The Case for Messy Multilateralism // Financial Times. 6 January.

Hamerow T. (1958). Restoration, Revolution, Reaction: Economics and Politics in Germany, 1815-1871. Princeton: Princeton University Press.

Hannah E., Scott J., Wilkinson R. (2018). The WTO in Buenos Aires: The Outcome and its Significance for the Future of the Multilateral Trading System // World Economy. Vol. 41. No. 10. P. 2578-2598.

Held D. (2003). From Executive to Cosmopolitan Multulateralism. Taming Globalization: Frontiers of Governance / D. Held, M. Koenig-Archibugi (eds). Cambidge: Polity Press.

Helleiner E. (2014a). Towards Cooperative Decentralization? The Post-Crisis Governance of Global OTC Derivatives // Transnational Financial Regulation After the Crisis / T. Porter (ed.). Abingdon: Routledge.

Helleiner E. (2014b). The Status Quo Crisis. Oxford: Oxford University Press.

Helleiner E. (2016). Legacies of the 2008 Crisis for Global Financial Governance // Global Summitry. Vol. 2. No. 1. P. $1-12$.

Hett F., Wien M. (eds) (2015). Between Principles and Pragmatism Perspectives on the Ukraine Crisis from Brazil, India, China and South Africa. Berlin: Perspective, Friedrich-Ebert-Stiftung.

Hicks M.J., Devtaj S. (2017). Myth and Reality of Manufacturing in America. Ball State Center For Business and Economic Research.

IISD (2018). Update on EU Trade and Investment Negotiations: Japan, Vietnam, Australia, New Zealand, Mexico. Investment Treaty News International Insitute for Sustainable Development, July 30. Режим доступа: https:// www.iisd.org/itn/2018/07/30/update-on-eu-trade-and-investment-negotiations-japan-vietnam-australia-new-zealand-mexico (дата обращения: 28.04.2019).

Johnson K. (2019). While Trump Isolates the U.S., It's 'Let's Make a Deal' for the Rest of the World Globalization is Alive and Well. It's Just the United States Sitting on the Sidelines. 3 July. Режим доступа: https:// foreignpolicy. com/2019/07/03/while-trump-isolates-u-s-its-lets-make-a-deal-for-the-rest-of-the-worldtrade-fta-merco-sur-eu (дата обращения: 28.04.2021).

Kahler M. (2016). Regional Challenges to Global Governance. The Council on Foreign Relations, Part of Discussion Paper Series on Global and Regional Governance.

Kirton J.J. (2013). G20 Governance for a Globalized World. Farnham: Ashgate.

Laïdi Z. (2012). BRICS: Sovereignty Power and Weakness // International Politics. Vol. 49. No. 5. P. 614-632.

Larionova M., Kirton J. (eds) (2018). BRICS and Global Governance. N. Y.: Routledge.

Larionova M., Shelepov A. (2015). Is BRICS Institutionalization Enhancing Its Effectiveness? The European Union and the BRICS. Complex Relations in the Era of Global Governance / M. Rewizorski (ed.). Heidelberg; N. Y.: Springer.

Leung K., Bond M.H. (1982). How Chinese and Americans Reward Task-related Contributions: A Preliminary Study // Psychologia. Vol. 25. No. 1. P. 32-39.

Leung K., Bond M.H. (1984). The Impact of Cultural Collectivism on Reward Allocation // Journal of Personality and Social Psychology. Vol. 47. No. 4. P. 793-804.

Little R. (2007). The Balance of Power in International Relations: Metaphors, Myths and Models. Cambridge: Cambridge University Press. 
Luckhurst J. (2018). The Shifting Global Economic Architecture. Decentralizing Authority in Contemporary Global Governance. Basingstoke: Palgrave Macmillan.

Lukov V. (2012). A Global Forum for the New Generation: The Role of the BRICS and the Prospects for the Future. Режим доступа: http://www.brics.utoronto.ca/analysis/Lukov-Global-Forum.html (дата обращения: 20.10.2018).

Marczewska-Rytko M. (1995). Populizm. Teoria i praktyka polityczna. Lublin: Wydawnictwo UMCS.

Mielniczuk F. (2013). BRICS in the Contemporary World: Changing Identities, Converging Interests // Third World Quarterly. Vol. 34. No. 6. P. 1075-1090.

Milliken J. (1999). The Study of Discourse in International Relations: A Critique of Research and Methods // European Journal of International Relations. Vol. 5. No. 2. 225-254.

Milner H. (1997). Interests, Institutions, and Information. Domestic Politics and International Relations. Princeton: Princeton University Press.

Milner H.V. (2018). Globalization and its Political Consequences: The Effects on Party Politics in The West. Paper for the annual APSA conference. August 2018. Boston MA. Режим доступа: https://scholar.princeton. edu/sites/ default/files/hvmilner/files/milner_globalization_political_consequences.pdf (дата обращения: 28.04.2021).

Moschella M., Weaver C. (2014). Handbook of Global Economic Governance. Players, power and paradigms. London; New York: Routledge.

Mudde C. (2004) The Populist Zeitgeist // Government and Opposition. Vol. 39. No. 4. P. 541-63. Available at: https://doi.org/10.1111/j.1477-7053.2004.00135.x

Mudde C., Rovira Kaltwasser C. (2012) Populism and (Liberal) Democracy // Populism in Europe and the Americas: Threat or Corrective for Democracy? / C. Mudde, C. Rovira Kaltwasser (eds). Cambridge: Cambridge University Press.

Neethling T. (2017). South Africa's Foreign Policy and the BRICS Formation: Reflections on the Quest for the 'Right' Economic-diplomatic Strategy // Insight on Africa. Vol. 9. No. 1. P. 39-61.

Olszyk S. (2007). "Vox populi vox Dei”: teoria populizmu politycznego // Annales Universitatis Paedagogicae Cracoviensis. Studia Politologica. Vol. 46. No. 3. P. 236-47.

Petersmann E.-U. (2018). How should the EU and Other WTO Members React to Their WTO Governance and WTO Appellate Body Crises? RSCAS 2018/71 Robert Schuman Centre for Advanced Studies Global Governance Programme-331, Florence: EUI.

Polanyi K. (1944). The Great Transformation: The Political and Economic Origins of Our Time. New York: Farrar\&Rineheart.

Rewizorski M. (2015). Participation of the European Union and the BRICS in the G-20. The European Union and the BRICS. Complex Relations in the Era of Global Governance / M. Rewizorski (ed.). Heidelberg; New York: Springer.

Rewizorski M. (2017). Dużo hałasu o nic? Uwagi o reformie modelu funkcjonowania Międzynarodowego Funduszu Walutowego. Przegląd Politologiczny. No. 2. P. 19-37.

Rodrik D (2018). Populism and the Economics of Globalization // Journal of International Business Policy. No. 1. Режим доступа: https://doi.org/10.1057/s42214-018-0001-4 (дата обращения: 28.04.2021).

Røren P., Beaumont P. (2019). Grading Greatness: Evaluating the Status Performance of the BRICS // Third World Quarterly. Vol. 40. No. 3. P. 429-450.

Rosenberg H. (1967). Große Depression und Bismarckzeit. Berlin: de Gruyter.

Russia Beyond (2016). Criticism of BRICS is Indicator of its Significance - Ryabkov. Режим доступа: https:// www. rbth.com/world/2016/02/08/criticism-of-brics-is-indicator-of-its-significance-ryabkov_565821 (дата обращения: 02.07.2019).

Sampson E.E. (1975). On Justice as Equality // Journal of Social Issues. Vol. 31. No. 3.

Schirm S.A. (2009). Ideas and Interests in Global Financial Governance: Comparing German and US preference formation // Cambridge Review of International Affairs. Vol. 22. No. 3. P. 501-521. 
Starmans C., Sheskin M., Bloom P. (2017). Why People Prefer Unequal Societies // Nature: Human Behaviour. Vol. 1. No. 4. P. 1-7.

Stern F. (1961). The Politics of Cultural Despair. Berkeley, CA: University of California Press.

Stuenkel O. (2014). Emerging Powers and Status: The Case of the First BRICs Summit // Global Governance. Vol. 38. No. 1. P. 89-109.

Stuenkel O. (2015). The Brics and the Future of Global Order. Lanham, MD: Lexington.

Tabuchi H., Ewing J. (2017). Europe and Japan Near Trade Deal as U.S. Takes Protectionist Path // New York Times. Режим доступа: https://www.nytimes.com/2017/06/23/business/europe-japan-trade-deal.html (дата обращения: 28.04.2021)

This article is part of the "Global Economic Governance - Actors, Areas of Influence, Interactions" research project (OPUS, 2016/23/B/HS5/00118) funded by the National Science Centre, Poland.

Viswanathan H.H.S., Soni S. (2017). BRICS Role in Global Governance Processes. A Decade of BRICS: Indian Perspectives for the Future / S. Saran (ed.). New Delhi: Observer Research Foundation. P. 9-18.

Walzer M. (1983). Spheres of justice: A defence of pluralism and equality. Oxford: Martin Robertson.

Wilson G.K. (2017). Brexit, Trump and the special relationship // The British Journal of Politics and International Relations. Vol. 19. No. 3. P. 543-557.

Wulf H., Debiel T. (2015). India's 'Strategic Autonomy' and the Club Model of Global Governance: Why the Indian BRICS Engagement Warrants a Less Ambiguous Foreign Policy Doctrine // Strategic Analysis. Vol. 39. No. 1. P. $27-43$.

Xing L. (2014). Introduction. Understanding the Hegemony and the Dialectics of the Emerging World Order. The BRICS and Beyond // The International Political Economy of Emergence of a New World Order / L. Xing (ed.). Farnham: Ashgate.

Zhang Y. (2018). The US - China Trade War: A Political and Economic Analysis // Indian Journal of Asian Affairs. Vol. 3. No. 1-2. 


\title{
Between Hyperglobalization and National Policy. Is There a Way to Mitigate Populist Risks for Global Economic Governance in the Post-COVID-19 World?
}

\author{
M. Rewizorski
}

Marek Rewizorski - Dr., Associate Professor in the Institute of Political Science, Faculty of Social Science, University of Gdańsk; 2C/15 ul. Wielkopolska, 78-100 Kolobrzeg, Poland; E-mail: marcuser@o2.pl

\begin{abstract}
Some scholars of global governance advocate rebalancing from global to national governance. They underline the incompatibility of global economic governance with democracies, which have the right to protect their social arrangements. They discern the fact that global (economic) governance is under heavy fire from a new vox populi, underscoring the socio-economic and cultural sources of their resentment and opposition to the liberal international order. While pointing at the timeliness of such argumentation, this article examines the fundamental problem with a sovereignty-related solution to the populist challenge. It lies in the fact that reconstituting global economic steering with a stronger emphasis on sovereignty may open the door for pursuing distinct national policies, which have blossomed during the Covid-19 pandemic and which not only overlap with populism but dismantle the benefits of international cooperation in the post-Covid-19 world. By asking about the role of the fragmented system of economic governance in inspiring populist resentment, this article creates an opportunity not only to address the challenges to global economic governance, but more specifically to reflect upon: the justification of decisive shifts toward national governance; risks which remain hidden for those discontented with economic globalization; and drafting an alternative solution, namely taking the middle way between hyper globalization and a more national policy.
\end{abstract}

Key words: global economic governance; integral governance; fragmentation; digitalization; sovereignty; populism; WTO; G20

For citation: Rewizorski M. (2021). Between Hyperglobalization and National Policy. Is There a Way to Mitigate Populist Risks for Global Economic Governance in the Post-COVID-19 World? International Organisations Research Journal, vol. 16, no 2, pp. 132-156 (in English). DOI: 10.17323/1996-7845-2021-02-07

\section{References}

Abdeneur A. (2016). Rising Powers and International Security: the BRICS and the Syrian Conflict. Rising Powers Quarterly, vol. 1, no 1, pp. 109-33. Available at: http://risingpowersproject.com/wp-content/uploads/2016/10/vol1.1.Adriana-Erthal-Abdenur.pdf (accessed 28 April 2019).

Arnold K.M. et al. (2011). Facing the Challenges. Three Scenarios for Global Economic Governance in 2020. Berlin: GG2020 Economic Governance Working Group.

Autor D., Dorn D., Hanson G. (2016). The China Shock: Learning from Labor Market Adjustment to Large Changes in Trade. Annual Review of Economics, vol. 8, pp. 205-40.

Baldwin D.A. (2002). Power and international relations. The Handbook of International Relations (W. Carlsnaes, T. Risse, B.A. Simmons (eds)). Thousand Oaks: Sage Press.

Barnett M.N., Duvall R. (2005). Power in International Politics. International Organization, vol. 59, no 1, pp. 39-75.

Barnett M.N., Duvall R. (2018). Organization and the Diffusion of Power. International Organization and Global Governance (T.G. Weiss, R. Wilkinson (eds)). New York: Routledge.

Beiser F.C. (2016). Weltschmerz. Pessimism in German Philosophy, 1860-1900. Oxford: Oxford University Press. 
Bertelsmann-Scott T. et al. The New Development Bank: Moving the BRICS from an Acronym to an Institution. South African Institute of International Affairs (SAIIA), Occasional Paper 233.

Bousquet A., Curtis S. (2011). Beyond Models and Metaphors: Complexity Theory, Systems Thinking and International Relations. Cambridge Review of International Affairs, vol. 24, no 1, pp. 43-62.

BRICS (2014). Agreement on the New Development Bank. Fortaleza, Brazil, July 15. Available at: http://www. brics.utoronto.ca/docs/140715-bank.html (accessed 10 October 2018).

Bucher B. (2014). Acting Abstractions: Metaphors, Narrative Structures, and the Eclipse of Agency. European Journal of International Relations, vol. 20, no 3, pp. 742-65.

Burgoon B. (2009). Globalization and Backlash: Polayni's Revenge? Review of International Political Economy, vol. 16, no 2, pp. 145-177.

Cienki A., Yanow D. (2013). Why Metaphor and other Tropes? Linguistic Approaches to Analysing Policies and the Political. Journal of International Relations and Development, vol. 16, no 2, pp. 167-76.

Cohen R.L., Greenberg J. (1982). The Justice Concept in Social Psychology. New York: Academic Press.

Cooper A.F., Farooq A.B. (2016). The Role of China and India in the G20 and BRICS: Commonalities or Competitive Behaviour? Journal of Current Chinese Affairs, vol. 45, no 3, pp. 73-106.

Cooper A.F., Thakur R. (2018). The BRICS in the Evolving Architecture of Global Governance. International Organization and Global Governance (T.G. Weiss, R. Wilkinson (eds)). New York: Routledge. 2nd ed.

Cox M. (2017). The Rise of Populism and the Crisis of Globalisation: Brexit, Trump and Beyond. Irish Studies in International Affairs, vol. 28, pp. 9-17.

Deutsch M. (1985). Distributive Justice: A Socio-Psychological Perspective. New Haven: Yale University Press. European Journal of International Relations, vol. 5, no 2, 225-54.

Frieden J. (2017). The Politics of the Globalization Backlash: Sources and Implications. Repared for Presentation at the Annual Meetings of the American Economics Association, Panel on "Making Globalization Inclusive," 6 January.

Guzzini S. (2005). A Concept of Power: A Constructivist Analysis. Millennium, vol. 33, no 3, pp. 495-521.

Haas R. (2010). The Case for Messy Multilateralism. Financial Times, 6 January.

Hamerow T. (1958). Restoration, Revolution, Reaction: Economics and Politics in Germany, 1815-1871. Princeton: Princeton University Press.

Hannah E., Scott J., Wilkinson R. (2018). The WTO in Buenos Aires: The Outcome and its Significance for the Future of the Multilateral Trading System. World Economy, vol. 41, no 10, pp. 2578-98.

Held D. (2003). From Executive to Cosmopolitan Multulateralism. Taming Globalization: Frontiers of Governance (D. Held, M. Koenig-Archibugi (eds)). Cambidge: Polity Press.

Helleiner E. (2014a). Towards Cooperative Decentralization? The Post-Crisis Governance of Global OTC Derivatives. Transnational Financial Regulation After the Crisis (T. Porter (ed.)). Abingdon: Routledge.

Helleiner E. (2014b). The Status Quo Crisis. Oxford: Oxford University Press.

Helleiner E. (2016). Legacies of the 2008 Crisis for Global Financial Governance. Global Summitry, vol. 2, no 1 , pp. 1-12.

Hett F., Wien M. (eds) (2015). Between Principles and Pragmatism Perspectives on the Ukraine Crisis from Brazil, India, China and South Africa. Berlin: Perspective, Friedrich-Ebert-Stiftung.

Hicks M.J., Devtaj S. (2017). Myth and Reality of Manufacturing in America. Ball State Center For Business and Economic Research.

IISD (2018). Update on EU Trade and Investment Negotiations: Japan, Vietnam, Australia, New Zealand, Mexico. Investment Treaty News International Insitute for Sustainable Development, July 30. Available at: https:// www.iisd.org/itn/2018/07/30/update-on-eu-trade-and-investment-negotiations-japan-vietnam-australia-new-zealand-mexico (accessed 28 April 2019).

Johnson K. (2019). While Trump Isolates the U.S., It's 'Let's Make a Deal' for the Rest of the World Globalization is Alive and Well. It's Just the United States Sitting on the Sidelines. 3 July. Available at: https://foreign- 
policy. com/2019/07/03/while-trump-isolates-u-s-its-lets-make-a-deal-for-the-rest-of-the-world-trade-ftamerco- sur-eu (accessed 4 July 2019).

Kahler M. (2016). Regional Challenges to Global Governance. The Council on Foreign Relations, Part of Discussion Paper Series on Global and Regional Governance.

Kirton J.J. (2013). G20 Governance for a Globalized World. Farnham: Ashgate.

Laïdi Z. (2012). BRICS: Sovereignty Power and Weakness. International Politics, vol. 49, no 5, pp. 614-32.

Larionova M., Kirton J. (eds) (2018). BRICS and Global Governance. New York: Routledge.

Larionova M., Shelepov A. (2015). Is BRICS Institutionalization Enhancing Its Effectiveness? The European Union and the BRICS. Complex Relations in the Era of Global Governance (M. Rewizorski (ed.)). Heidelberg; New York: Springer.

Leung K., Bond M.H. (1982). How Chinese and Americans Reward Task-related Contributions: A Preliminary Study. Psychologia, vol. 25, no 1, pp. 32-9.

Leung K., Bond M.H. (1984). The Impact of Cultural Collectivism on Reward Allocation. Journal of Personality and Social Psychology, vol. 47, no 4, pp. 793-804.

Little R. (2007). The Balance of Power in International Relations: Metaphors, Myths and Models. Cambridge: Cambridge University Press.

Luckhurst J. (2018). The Shifting Global Economic Architecture. Decentralizing Authority in Contemporary Global Governance. Basingstoke: Palgrave Macmillan.

Lukov V. (2012). A Global Forum for the New Generation: The Role of the BRICS and the Prospects for the Future. Available at: http://www.brics.utoronto.ca/analysis/Lukov-Global-Forum.html (accessed 20 October 2018).

Marczewska-Rytko M. (1995). Populizm. Teoria i praktyka polityczna. Lublin: Wydawnictwo UMCS.

Mielniczuk F. (2013). BRICS in the Contemporary World: Changing Identities, Converging Interests. Third World Quarterly, vol. 34, no 6, pp. 1075-90.

Milliken J. (1999). The Study of Discourse in International Relations: A Critique of Research and Methods.

Milner H. (1997). Interests, Institutions, and Information. Domestic Politics and International Relations. Princeton: Princeton University Press.

Milner H.V. (2018). Globalization and its Political Consequences: The Effects on Party Politics in The West. Paper for the annual APSA conference, August 2018, Boston MA. Available at: https://scholar.princeton.edu/ sites/default/files/hvmilner/files/milner_globalization_political_consequences.pdf (accessed 2 July 2019).

Moschella M., Weaver C. (2014). Handbook of Global Economic Governance. Players, power and paradigms. London; New York: Routledge.

Mudde C. (2004) The Populist Zeitgeist. Government and Opposition, vol. 39, no 4, pp. 541-63. Available at: https://doi.org/10.1111/j.1477-7053.2004.00135.x

Mudde C., Rovira Kaltwasser C. (2012) Populism and (Liberal) Democracy. Populism in Europe and the Americas: Threat or Corrective for Democracy? (C. Mudde, C. Rovira Kaltwasser (eds)). Cambridge: Cambridge University Press.

Neethling T. (2017). South Africa's Foreign Policy and the BRICS Formation: Reflections on the Quest for the 'Right' Economic-diplomatic Strategy. Insight on Africa, vol. 9, no 1, pp. 39-61.

Olszyk S. (2007). "Vox populi vox Dei”: teoria populizmu politycznego. Annales Universitatis Paedagogicae Cracoviensis. Studia Politologica, vol. 46, no 3, pp. 236-47.

Petersmann E.-U. (2018). How should the EU and Other WTO Members React to Their WTO Governance and WTO Appellate Body Crises? RSCAS 2018/71 Robert Schuman Centre for Advanced Studies Global Governance Programme-331, Florence: EUI.

Polanyi K. (1944). The Great Transformation: The Political and Economic Origins of Our Time. New York: Farrar\&Rineheart. 
Rewizorski M. (2015). Participation of the European Union and the BRICS in the G-20. The European Union and the BRICS. Complex Relations in the Era of Global Governance (M. Rewizorski (ed.)). Heidelberg; New York: Springer.

Rewizorski M. (2017). Dużo hałasu o nic? Uwagi o reformie modelu funkcjonowania Międzynarodowego Funduszu Walutowego. Przegląd Politologiczny, no 2, pp. 19-37.

Rodrik D (2018). Populism and the Economics of Globalization. Journal of International Business Policy, no 1. Available at: https://doi.org/10.1057/s42214-018-0001-4 (accessed 2 July 2019).

Røren P., Beaumont P. (2019). Grading Greatness: Evaluating the Status Performance of the BRICS. Third World Quarterly, vol. 40, no 3, pp. 429-50.

Rosenberg H. (1967). Große Depression und Bismarckzeit. Berlin: de Gruyter.

Russia Beyond (2016) Criticism of BRICS is Indicator of its Significance - Ryabkov. Available at: https://www. rbth.com/world/2016/02/08/criticism-of-brics-is-indicator-of-its-significance-ryabkov_565821 (accessed 2 July 2019).

Sampson E.E. (1975). On Justice as Equality. Journal of Social Issues, vol. 31, no 3.

Schirm S.A. (2009). Ideas and Interests in Global Financial Governance: Comparing German and US preference formation. Cambridge Review of International Affairs, vol. 22, no 3, pp. 501-21.

Starmans C., Sheskin M., Bloom P. (2017). Why People Prefer Unequal Societies. Nature: Human Behaviour, vol. 1, no 4, pp. 1-7.

Stern F. (1961). The Politics of Cultural Despair. Berkeley, CA: University of California Press.

Stuenkel O. (2014). Emerging Powers and Status: The Case of the First BRICs Summit. Global Governance, vol. 38, no 1, pp. 89-109.

Stuenkel O. (2014). Emerging Powers and Status: The Case of the First BRICs Summit. Global Governance, vol. 38, no 1, pp. 89-109.

Stuenkel O. (2015). The Brics and the Future of Global Order. Lanham, MD: Lexington.

Tabuchi H., Ewing J. (2017). Europe and Japan Near Trade Deal as U.S. Takes Protectionist Path. New York Times. Available at: https://www.nytimes.com/2017/06/23/business/europe-japan-trade-deal.html (accessed 4 July 2019).

This article is part of the "Global Economic Governance - Actors, Areas of Influence, Interactions" research project (OPUS, 2016/23/B/HS5/00118) funded by the National Science Centre, Poland.

Viswanathan H.H.S., Soni S. (2017). BRICS Role in Global Governance Processes. A Decade of BRICS: Indian Perspectives for the Future (S. Saran (ed.)). New Delhi: Observer Research Foundation, pp. 9-18.

Walzer M. (1983). Spheres of justice: A defence of pluralism and equality. Oxford: Martin Robertson.

Wilson G.K. (2017). Brexit, Trump and the special relationship. The British Journal of Politics and International Relations, vol. 19, no 3, pp. 543-57.

Wulf H., Debiel T. (2015). India's 'Strategic Autonomy' and the Club Model of Global Governance: Why the Indian BRICS Engagement Warrants a Less Ambiguous Foreign Policy Doctrine. Strategic Analysis, vol. 39, no 1 , pp. 27-43.

Xing L. (2014). Introduction. Understanding the Hegemony and the Dialectics of the Emerging World Order. The BRICS and Beyond. The International Political Economy of Emergence of a New World Order (L. Xing (ed.)). Farnham: Ashgate.

Zhang Y. (2018). The US - China Trade War: A Political and Economic Analysis. Indian Journal of Asian Affairs, vol. 3, no 1-2. 